Review

\title{
Forty Years of Forensic Interviewing of Children Suspected of Sexual Abuse, 1974-2014: Historical Benchmarks
}

\section{Kathleen Coulborn Faller}

School of Social Work, University of Michigan, 1080 S. University Ave, Ann Arbor, MI 48109-1106, USA; E-Mail: kcfaller@umich.edu; Tel.: +1-734-649-5452

Academic Editor: Nigel Parton

Received: 14 October 2014 / Accepted: 2 December 2014 / Published: 24 December 2014

\begin{abstract}
This article describes the evolution of forensic interviewing as a method to determine whether or not a child has been sexually abused, focusing primarily on the United States. It notes that forensic interviewing practices are challenged to successfully identify children who have been sexually abused and successfully exclude children who have not been sexually abused. It describes models for child sexual abuse investigation, early writings and practices related to child interviews, and the development of forensic interview structures from scripted, to semi-structured, to flexible. The article discusses the controversies related appropriate questions and the use of media (e.g., anatomical dolls and drawings). It summarizes the characteristics of four important interview structures and describes their impact of the field of forensic interviewing. The article describes forensic interview training and the challenge of implementing training in forensic practice. The article concludes with a summary of progress and remaining controversies and with future challenges for the field of forensic interviewing.
\end{abstract}

Keywords: child sexual abuse; forensic interviewing; anatomical dolls; questioning children about abuse

\section{Introduction}

The mid-1970s marked a renewed awareness of the extent and seriousness of child sexual abuse. In the United States, this awareness was related to concern about child maltreatment in general [1], to the pioneering research of David Finkelhor on the prevalence of child sexual abuse among college students in six New England colleges and universities [2], and to social justice movements, for example the women's movement and the civil rights movement [3]. This article will describe the unique and 
important response to child sexual abuse, the forensic interviewing of children as a method to determine if they have been sexually abused. The article will focus primarily on forensic interviewing in the U.S., but with reference to parallel developments and collaborations involving other developed countries.

Who are the forensic interviewers? In the U.S., the first forensic interviewers were professionals with mental health backgrounds [4], but they are not the professionals who are mandated investigators of child sexual abuse; child protection workers and law enforcement officers are. In addition, the Children's Advocacy Center movement in the U.S. led to a new group of professionals, specially trained forensic interviewers, whose role initially was to interview children alleged to have been sexually abused, but over time, they have come to be responsible for interviewing children alleged to have been maltreated in other ways [5].

In this article, I will first address the impact of professional and public perceptions about the credibility of sexual abuse allegations on forensic interviewing practices and its effect on forensic interviewing. Second, I will describe the policy initiative in the United States that led to the need to evaluate children's allegations of sexual abuse. Third, I will briefly describe models for evaluating child sexual abuse in the U.S. Fourth, I will discuss early writing that defined interviews of alleged sexual abuse victims. Fifth, I will describe the development of forensic interviewing structures. Sixth, I will discuss select influential interview structures. Seventh, current endeavors to train child forensic interviewers will be documented; included in this discussion will be challenges related to the implementation of training in actual interview practice. Finally, in the conclusions, progress to date and remaining controversies will be summarized. Then modest proposals for future practice and research will be covered.

\section{Belief and Disbelief about Child Sexual Abuse: Impact on Forensic Interviewing}

Professional and public belief and disbelief about allegations of child sexual abuse have varied over the course of history [6]. The source of the ebb and flow in belief is complex. In part, it derives from the inability of adults to accept that sexual abuse of children occurs and a counter reaction of rage when sexual victimization is believed [7]. In the domain of forensic interviewing these complex reactions have resulted in a tension between using interview practices that enable disclosure and interview practices that avoid false allegations [8].

In the mid-1970s, when sexual abuse was "rediscovered" [1], the initial professional response was to gather information about sexual abuse "by any means necessary". The means included interviewing the child multiple times, asking leading questions, and using other suggestive techniques [9].

In the mid-1980s, however, concerns about false allegations began to drive interview practices. Events that led to this "backlash" were are series of multi-victim cases $[10,11]$. In the United States, most of these cases involved day care centers. The cases received a great deal of media attention, initially focused on the enormity of harm to children [12] and later highlighting questionable interview practices and doubting children's disclosures [13]. There were comparable cases in England, for example one in Cleveland [14] and in Scotland, a case on the Orkney Islands [15].

Professional views about the veracity of the sexual and other abuse described in these multi-victim cases remains mixed [16]. Nevertheless, these high profile cases have played a major role in shaping forensic interview practice. They have driven interview strategies that avoid false positives (children 
determined to have been sexually abused, but who were not) as opposed to false negatives (children who were sexually abused, but were not identified in the investigative process) [8].

\section{The Challenge of the Child Abuse Prevention and Treatment Act}

In the United States, the passage of the Child Abuse Prevention and Treatment Act in 1974 (CAPTA) [17] had implications for child welfare policy and practice beyond what the U.S. Congress could have anticipated. Among other provisions in CAPTA that transformed the child welfare system was mandated reporting of child maltreatment. This provision in federal law both expanded the professions who were mandated to report and the types of maltreatment to be reported. Subsequent to the passage of CAPTA, virtually every state amended or promulgated a state law to comply with CAPTA. States did this because there were federal discretionary funds tied to a state statute in compliance with CAPTA provisions [17].

Mandated reporting resulted in an exponential increase in reports of suspected child maltreatment to local child protection agencies. In 1978, the first year of data collection under CAPTA, fewer than 700,000 cases, or 10.1 per 1000 children, were reported [18]. In 2012, the most recent year for which there are aggregated data, there were 3.4 million cases reported involving approximately 6.3 million children, 46.1 per 1000 children [19].

Although initially sexual abuse was not among the required types of child maltreatment to be reported, it was added in 1981 [20]. This addition resulted in states amending their statutes to include sexual abuse as a reportable type of child maltreatment [21]. Unlike physical abuse, which is usually determined by the pattern of a child's injuries, and physical neglect, which is usually determined by a child's physical condition or living conditions, as a rule, child sexual abuse rarely leaves physical signs. Physical indicators are found in about $10 \%$ of girls and rarely in boys [22]. Sexual abuse is generally determined by the child's statements and sometimes by the child's behavior [23]. Child welfare professionals were therefore tasked with gathering information from children to determine whether they had been sexually abused.

\section{Models for Investigation}

In this this section, models that have evolved in the United States for investigating allegations of sexual abuse and their rationale will be discussed. This article focuses on the forensic interview, but the result of this interview are only one piece of information gathered during the investigation and should be regarded as a means to the end of understanding what sexual abuse, if any, the child has experienced. That said, although the forensic interview is once piece, it is the centerpiece of the investigation.

\subsection{An Early Approach to Investigation of Sexual Abuse}

In the early days post-CAPTA, child welfare professionals followed their own intuition in data gathering about possible child sexual abuse [24]. For example, the model for investigating physical abuse or neglect involved child protection investigators going to the home and "confronting" the parents with the allegations. Applying this model to sexual abuse cases, child welfare professionals were interviewing children in the presence of their parents, when the alleged abuser was in the family [25]. Soon, however, 
professionals came to understand that children were unlikely to disclose sexual abuse in the presence of the perpetrator.

\subsection{School-Based Interviews by First Responders}

Because in-home investigations were ineffective, communities and states developed policies for interviewing school-aged children in school and informing their caretakers after the child interview [26]. Interviewing children in their school setting remains an important approach for first responders, who may be child protection workers or law enforcement. Depending upon the resources in the community, an interview by the first responder may be followed by a joint investigation or a forensic interview at a Children's Advocacy Center, both described below.

This model, however, does not address investigation of cases of pre-school children who may have been sexually abused. This child population remains a serious challenge for both mandated investigators and forensic interviewers. Children ages four and older have been successfully interviewed [27], but younger children may also be victims of sexual abuse and lack the verbal and non-verbal skills to communicate their experiences in a forensic interview [28-30]. They remain a population in need of protection.

\subsection{Joint Investigation by Child Protection and Law Enforcement}

Child sexual abuse is not only harmful to the child, jeopardizing child safety and well-being; it is also a crime. Cases in which the offender is in the family and those that involve caretakers who are negligent and fail to protect children in their care from sexual abuse fall within the purview of child protective services. Cases where caretakers are not culpable are the responsibility of law enforcement. Sexual abuse prevalence studies indicate that about $70 \%$ of offenses are extra familial [31]. In the mid-1980s, virtually every state in the U.S. amended its child protection laws to foster collaboration between law enforcement and child protection investigators on sexual abuse cases, and often on other serious maltreatment cases [32,33]. Joint investigation models involving child protection, law enforcement, and the local prosecutor for intra-familial sexual abuse cases were developed. These models vary by locality. Child protection workers and law enforcement might jointly interview the child, often one or the other taking the lead [32]. The case might be divided so that the child protection worker interviews the child and law enforcement the alleged offender along with other witnesses. Information might be shared through exchange of notes, sharing of interview recordings, or conferring [32]. If there is a Children's Advocacy Center in the community, the model described in the next section usually will be followed.

\subsection{The Development of the Children's Advocacy Center Model}

Because investigation of child sexual abuse may involve a range of professionals - for example, child protection workers, medical professionals, law enforcement, and prosecutors, children were often interviewed multiple times in multiple contexts [34]. The process of having to repeatedly disclose what was, for many children, a shameful and frightening experience, to multiple adult strangers was felt to be traumatic.

As a response to the above troubling scenario, in 1985, Huntsville, Alabama, District Attorney Bud Cramer announced a new concept, a Children's Advocacy Center (CAC), a child friendly place, where 
alleged victims of sexual abuse would receive a single interview by a trained professional. The interview could be observed, either through a one-way mirror or on a remotely located TV monitor, by all the professionals who needed to hear the child's account [34]. Moreover, other services the child required were intended to be located at the Children's Advocacy Center, so the child experienced "one stop shopping." These services might include a medical exam, victim advocacy, and treatment. The National Children's Advocacy Center (NCAC) was thus founded in Huntsville, Alabama, and continues to be located in Huntsville. NCAC plays a leadership role in knowledge development and dissemination related to forensic interview models and structures, through its annual International Symposium, its on-site and remote training endeavors, and its internet webinars. NCAC conducts about 600 child interviews per year [35] and houses an electronic library, Child Abuse Library Online (CALiO) on child maltreatment that serves the professional community [36].

Not only did the concept of a Children's Advocacy Center (CAC) resonate with professionals charged with investigating child sexual abuse, but CACs became widespread because, in 1990, District Attorney Bud Cramer became U.S. Congressman Bud Cramer. One of his first acts as a Congressman was to foster a bill to fund CACs [36]. To date, there are over 800 CACs in all 50 states and in 10 countries. Two-thirds of the communities in the United States now have access to a Children's Advocacy Center [37]. So far, this funding has been sustained.

The National Children's Alliance (NCA) administers the funding for CACs and has established a set criteria that Children's Advocacy Centers must meet to obtain funding. Today, for a CAC to be an accredited member of the National Children's Alliance and receive federal funding, organizations must have: (1) Child-Appropriate/Child-Friendly Facility; (2) Multidisciplinary Team (MDT), which includes representation from law enforcement, child protective services, prosecution, mental health, medical, victim advocacy, and the Children's Advocacy Center; (3) Organizational Capacity, both fiscal and programmatic to sustain the CAC; (4) Cultural Competency and Diversity, acknowledged and hopefully integrated into its investigative and interviewing endeavors; (5) Forensic Interviews; (6) Medical Evaluations; (7) Therapeutic Intervention; (8) Victim Support/Advocacy; (9) Case Review; and (10) Case Tracking [38]. Not all of these services need be provided at the CAC. For example, medical exams are frequently undertaken off-site.

In terms of forensic interviews, the National Children's Alliance requires that interviews be "conducted in a manner that is legally sound, of a neutral, fact-finding nature, and are coordinated to avoid duplicative interviewing" [38]. NCA does not endorse a particular forensic interview model or structure.

Subsequent to the emergence of NCAC, one of the earliest and most influential CACs was the CornerHouse Interagency Child Abuse Evaluation Center. Like NCAC, leadership for the development of CornerHouse came from the county attorney's office, which, in 1986, sent representatives to visit the NCAC in Huntsville [39].

\section{Early Writings about Forensic Interviewing}

In this section, the pioneering role of the Kempe Center, early research on forensic interviewer practices, the leadership role of the U.S. Government, and the International Interdisciplinary Consensus Statement will be described. 


\subsection{Kempe Center Advice}

One of the earliest written guides for professionals interviewing children about sexual abuse came from the C. Henry Kempe National Center for the Prevention and Treatment of Child Abuse and Neglect [4]. In 1985, David Jones, who was Associate Director, and Mary McQuiston, who directed the therapeutic pre-school at the Kempe Center, wrote a 44 page pamphlet published by the Kempe Center entitled Interviewing the Sexually Abused Child. Despite its brevity, it was prescient in identifying and offering guidance about key interview and investigative issues. The pamphlet documented the extent and effects of sexual abuse, provided a summary of relevant research, laid out a framework for gathering information about the sexual abuse allegation, provided advice about the interview process, and suggested criteria to be used to "validate" the allegation. This pamphlet was revised twice, the last time in 1989 and is no longer in print [40].

The authors advised review of background information before the interview, a practice that has led to debate because of concerns that prior knowledge could bias the interviewer [41], but now is considered best practice and is incorporated into most interview protocols [23,27]. Jones and McQuiston advised against having a parent present in the interview room, but rather assuring the child knew where the caretaker was and allowing the child to check in with the parent, if needed, during the interview process. The authors favored audio and video recording but acknowledged that prosecutors might oppose taping because of potential inconsistencies in the child's disclosures and potential challenges to interview techniques.

In terms of interview structure, they advise a simple (beginning, middle, end), flexible one that could be tailored to the allegations and the child. The interviewer should begin by explaining his/her role and building rapport by asking the child about salient issues in the child's life. The middle was the abuse-related part of the interview, and the end was closure. Consistent with current guidelines related to abuse inquiry, Jones and McQuiston recommended beginning with general, open-ended questions and only using more specific questions if the general ones did not assist in resolving the allegation. Moreover, they instructed the interviewer to follow an affirmative response to a specific question with an open-ended probe. Interviewers were to endeavor to gain details about the "who", "what", "when" and "where", but avoid asking the child "why", advice that is still good today.

Areas where Jones and McQuiston's advice differed from subsequent practice were recommending more than a single interview, advising the use of media, such as anatomical dolls, drawings, free drawings, and books about good and bad touch, and allowing time in the assessment for observation of the child in free play. Finally the authors suggested many more toys in the interview room than is current practice [4].

\subsection{Initial Research on Interview Practice}

A pioneering study to document practices for interviewing children about possible sexual abuse was undertaken by Conte, Sorensen, Fogarty, and Dalla Rosa [42]. They endeavored to gather data from a national sample of professionals assessing children for sexual abuse. Of the 212 respondents to their survey, $40 \%$ were child protection workers, $46 \%$ mental health professionals, and $14 \%$ other professionals, including police officers and states attorneys. Seventy-nine percent were female, and on average they 
had 8.8 years of experience working with sexually abused children. Most documented their interviews with written notes, but approximately a third endorsed the use of both audio and videotaping.

Just under half of respondents interviewed the "non-offending" parent before interviewing the child, and about half sometimes interviewed the child in the presence of the non-offending parent. Interview media played a prominent role in child interviews of these experts. Ninety-two percent employed anatomical dolls; half used other dolls; two-thirds used anatomical drawings; 87\% used free drawings, and about half used puppets [42].

Having a parent in the room and the extensive use of media, especially anatomical dolls, during interviews are not currently considered optimal practice [27]. Nonetheless, this research documented contemporary practice among a national sample of child sexual abuse experts and is important in understanding the evolution of forensic interviewing.

\subsection{Federal Leadership}

Another important provision of CAPTA was the establishment of the National Center on Child Abuse and Neglect (NCCAN) within the U.S. Department of Health and Human Services' Children's Bureau [17]. NCCAN played a leadership role in both child welfare policy and practice. Among its endeavors was the development of the Child Abuse and Neglect User Manual Series, intended to provide guidance to child welfare professionals in all domains of child maltreatment [43]. In 1993, NCCAN published a User Manual on child sexual abuse [7]. This User Manual addresses a spectrum of issues, including: (1) The emotional impact of working in the field of sexual abuse; (2) The scope, effects, and definitions of sexual abuse; (3) A general structure for investigations; (4) Child interviews; and (5) Treatment of the victim and family. Because the manual was developed for professionals in the child welfare field, which primarily addresses intra familial maltreatment, the manual offers guidance about psycho-social interviews with the non-offending parent and the alleged offender, as well as the child.

The chapter on the child interview suggests that interviews not be limited to a single interview, provides advice about appropriate questions, suggests guidelines about the use of media or props during interviews, and outlines a strategy for deciding about the likelihood of sexual abuse. This chapter provides a continuum of 5 types of questions from open-ended to close-ended for the interviewer to employ during inquiry about possible sexual abuse: (1) General questions (about the child's well-being); (2) Focused questions (on people, body parts, and circumstance of sexual abuse); (3) Multiple-choice questions; (4) Yes/no questions; and (5) Leading questions. Further, the manual admonishes the interviewer to use the most open-ended questions first and place more confidence in information elicited from more open-ended questions and correspondingly less confidence in information from more close-ended questions [7]. It, nevertheless, advises the interviewer, if faced with the prospect of not being able to resolve the allegation or asking a close-ended question, to ask a close-ended question.

Media or props are also discussed in the child interview chapter, as are instructions for their use. Media include: (1) Anatomical dolls, citing both their disadvantages and advantages; (2) Anatomical drawings; (3) Picture drawing; and (4) The dollhouse [7].

This is the first interview publication to articulate a continuum of questions, an issue that has been addressed more extensively in subsequent guides. Extensive use of media was soon to be dropped from advice to interviewers. 


\subsection{The International Consensus Statement}

In 1993, there was a meeting of experts on child sexual abuse from Europe, North America, and the Middle East to develop consensus about child sexual abuse assessment. The meeting resulted in a document entitled "The investigation of child sexual abuse: An international, interdisciplinary consensus statement", which was drafted by Michael Lamb, revised based upon the meeting participants' feedback, and subsequently published in three scholarly journals: Family Law Quarterly, Child Abuse \& Neglect: the International Journal and Journal of Child Sexual Abuse. The document was co-signed by 20 of the participants in the meeting. It represented the state of knowledge about child sexual abuse, including the scope of the problem, behavioral indicators of sexual abuse, interviewing child victims, use of dolls and other props during interviews, and the medical examination [44].

Recommendations regarding interviewing included interviewing the child as soon as possible after the alleged abuse, using open-ended questions designed to elicit a narrative, but with an acknowledgement that direct and focused questions may also be needed, especially with young children, and recording of interviews, preferably video recording. With regard to the use of dolls and other props, the consensus statement notes that they can be useful with children under 5, with reluctant children, and with uncommunicative children. The consensus statement supports a wide range of props, including anatomical dolls and anatomical drawings. The statement cites the importance of training and skill for interviewers using props and warns that anatomical dolls may elicit sexualized play from non-abused children. Such play is regarded as a red flag but not conclusive of sexual abuse in most cases [44].

\section{The Development of Interview Structures}

In the 1990s, professionals began to appreciate that interview guidance needed to involve more than mere advice about questions and the use of media; child welfare professionals needed advice about the structure of the interview, itself. This necessity derived from the characteristics of the interviewers and the interviewees.

Most professionals charged with the responsibility of interviewing children about sexual abuse did not have extensive mental health backgrounds or knowledge about child development. This was especially true of law enforcement, but might also have been true of child protection workers because the usual requirement for the position was a bachelor's degree, which could be in criminal justice [45]. Moreover, forensic interviewers at CACs did not necessarily have mental health or child development training.

Interviewees needed guidance because they were children. For most of them, an interview about sexual abuse is an anomalous and possibly frightening experience. Children needed to know what the expectations for the interview were. Moreover, bewildering for most children was the request to provide a narrative about their abuse experience instead of responding to short answer questions.

Below I will describe the development of interview structures, variations in their flexibility, and three notable components of these structures, providing children with ground rules, truth/lie strategies, and categorizing interview questions. 


\subsection{The Proliferation of Forensic Interview Structures}

Beginning in the 1990s, dozens of interview structures were developed [46], most with a focus on the mandated investigators - child protection and law enforcement, and on forensic interviewers at Children's Advocacy Centers. Some interview structures were developed in academic institutions, for example, the Stepwise Interview [47], the Cognitive Interview [48], and the Ten Step Investigative Interview [49]. Others were developed by agencies charged with interviewing children, for example, the National Children's Advocacy Center [50] and CornerHouse [51]. Eventually, states began developing interview protocols to be used by first responders and CAC forensic interviewers in their state. Examples are Oregon [52], Michigan [53] and Washington State Child Interview Guide [54].

\subsection{Degree of Flexibility of the Interview Structure}

Interview structures vary from scripted (e.g., Ten Step Investigative Interview [49], NICHD [27]), to semi-structured (e.g., RATAC [51], ChildFirst [55], Poole and Lamb's Investigative Interview [56]), to flexible (e.g., Faller's Child-Focused Flexible Interview [21], National Children's Advocacy Center Forensic Interview Protocol [50]). RADAR (Recognizing Abuse Disclosure types and Responding), which builds upon the NICHD protocol and research, is unique in that it has a scripted version for inexperienced interviewers and a semi-structured version for more experienced interviewers [57]. Moreover, RADAR provides the interviewer with a decision tree that takes into account possible barriers to disclosure, whether there has been a prior disclosure, and any prior allusion to abuse [57].

Scripted interview structures provide verbatim what the interviewer should say. During the abuse-related phase of the interview, however, when the interviewer is gathering information about the specifics of abusive experiences, the guidance is less prescriptive. Most scripted structures are linear; that is, they assume the interviewer will be able to move through the phases or stages in the order they are designated in the interview structure.

Semi-structured interview guides provide the interviewer with advice about various tasks, for example, the use of anatomical or other drawings, but indicate that the interviewer should decide whether to incorporate such components based upon the individual child, for example, the child's developmental stage, his/her comfort level, or specifics of the allegations [51].

Flexible interview structures take into consideration local community practices and state legal requirements (NCAC) [50], which may specify aspects of the interview structure. Faller points out that an interview structure is a two-edged sword [46]. It offers needed guidance to the interviewer, but the structure can also be used to challenge the interviewer who fails to follow the structure. The more prescriptive the structure, the greater the risk that the interviewer will deviate. This is because interviewers also try to follow the child's lead, and the child does not know the structure. Because of concern that the structure may be used against the interviewer, she argues for simpler structure. For example, an interview structure with a beginning, middle, and end allows for greater flexibility than one with many phases (e.g., the Step-wise Interview [47], Ten Step Investigative Interview [49]). 


\subsection{Interview Ground Rules}

Two issues influenced the development of interview ground rules. First, research has documented that children perform better in a forensic interview if they know what the expectations are [58]. Second, professionals thought rules would assure that children provided accurate information during forensic interviews. The number of ground rules varies by interview structure (4-9 rules). Some structures have fewer rules, in part because the interview structure developers were concerned that the child would not be able to remember and apply a lot of rules. One way some protocols have addressed this problem is by having children practice the rule as it is given. For example, the NICHD Protocol [27], which only has four rules, has the child practice each one of them. The order in which the ground rules are provided to the child varies. Below are ground rules found in interview structures.

(1) "I am going to ask you a lot of questions. If you know the answer, tell me" [21]. Many protocols fail to instruct the child to tell, if they know.

(2) "If you don't know the answer, say I don't know." "Don't guess." Both the NICHD [27] and the Ten Step [49] give the child an opportunity to demonstrate this skill by asking the child, "What is my dog's name?" The Ten Step then gives the child the opportunity to demonstrate his/her ability to answer a question, "Do you have a dog?" This is information the child knows.

(3) "If I ask you a question you don't understand, tell me and I'll ask it is a better way." Both the Ten Step Protocol [49] and RADAR [57] use the example, "What is your gender?" to give the child an opportunity to say they don't understand. The child is then asked to say whether he/she is a boy or a girl, a question the child understands.

(4) "If I make a mistake, tell me." Or "If I say something that's wrong, tell me." This rule is included to give children permission to correct interviewer error [47].

(5) "Even if you think I already know something, please tell me anyway [58]." Some protocols add "I wasn't there" [48]. This rule is included both because of concerns the child might assume the interviewer already knows what happened (and often they do) and because the goal of the forensic interview is to get information directly from the child. Some interview structures add that the child should provide details, even if the child does not think they are important (e.g., Cognitive Interview [48], Achieving the Best Evidence [59]).

Some interview structures give the child permission not to answer a question if it makes him/her uncomfortable. For example, the Step-wise Interview Protocol includes the rule: "If you feel uncomfortable at any time, please tell me or show me with the stop sign" [47]. Similarly, some structures include the rule, "If I ask the same question more than once, that doesn't mean your first answer was wrong. Sometimes I forget” (Cognitive Interview [48]).

\subsection{Truth/Lie Competency}

One of the strategies intended to assure children tell the truth is to have a discussion of the truth and lie during the ground rules part of the interview. Informative research on children's capacity to differentiate truth-telling from lying was undertaken by Thomas Lyon and Karen Saywitz [60]. They tested 96 children, ages 4-7, under the jurisdiction of the Los Angeles County Dependency Court, on three tasks: (1) Children were asked to define the truth and a lie; (2) Children were asked to tell the 
difference between a truth and a lie; and (3) Children were given 4 examples and asked to tell the researcher whether each was the truth or a lie. The children did quite poorly at tasks 1 and 2, but older children did better. All children performed much better on the identification of examples of the truth and lie, especially the 6 and 7 year olds $[60,61]$.

This research has led interview structure developers to include examples of true and false statements in the rules phase of the interview. For example, the NICHD Protocol instructs the interviewer to ask the child if the interviewer's shoes are red and whether he/she is standing up [27]. Lyon and Saywitz [62,63] have developed a series of pictured examples with accompanying text to use in truth/lie competency assessment. These are available through the University of Southern California Law School website under Thomas Lyon and can be downloaded free of charge [62]. That said, Lyon, who is the developer of the Ten Step Investigative Interview Protocol, does not include the truth/lie exercise in the Ten Step [49].

Nevertheless, analogue research has found that getting children to promise to tell the truth increases their likelihood of doing so [58 ${ }^{1}$. Thus, the Ten Step Protocol includes "Do you promise that you will tell the truth? Will you tell me any lies?" [49] Some protocols, for example ChildFirst [55], give the interviewer the option of including the truth or lie exercise.

\subsection{Interview Questions}

All interview structures provide guidance about appropriate questions/probes/prompts, and there is general agreement that open-ended questions are superior to close-ended ones $[27,58]$. The specific terms used to label a given type of question/probe are not consistent across interview structures, and there is not complete consensus about where on the question/probe continuum different types of interviewer utterances fall. Moreover, some interviewer structures prefer probes (e.g., tell me) rather than questions (e.g., can you tell me? do you remember?). Those preferring the probe strategy are concerned that the question strategy will give the child an out to say "no" [64]. Those that prefer a question strategy are concerned that the "tell me" approach will be experienced by the child as coercive and/or may compel the child to respond even though the child does not know the answer [64]. Below is a table (Table 1) which attempts to take into account dominant interview structure ${ }^{2}$ terms ${ }^{3}$ and definitions and provides a continuum, generally from most preferred to least preferred questions/probes. The continuum is structured from most open-ended to most close-ended and suggests forensic interviewers place more confidence in responses to open-ended questions/probes and correspondingly less confidence in responses to more close-ended questions/probes.

1 Although some analogue studies involve children with a history of maltreatment [60], there are no field studies using the promise to tell the truth. This is because it is very difficult to develop a research sample that consists of abuse allegations that the researcher knows what happened.

2 These terms derive from the NICHD protocol, the Ten Step Investigative Interview Guide, the NCAC Interview, RADAR, RATAC, APSAC Practice Guidelines for Psychosocial Evaluation of Suspected Sexual Abuse, the Memorandum of Good Practice and its revision, Achieving the Best Evidence, and ChildFirst.

3 When more than one term is used for a question/probe, the Continuum will include all terms. 
Table 1. Question/ Probe Continuum.

\begin{tabular}{|c|c|c|}
\hline Open-Ended & & More Confidence \\
\hline Type of Question/Probe & Definition & Examples \\
\hline $\begin{array}{l}\text { Rapport building } \\
\text { question/Probe }\end{array}$ & $\begin{array}{l}\text { Open-ended inquiry about the child's } \\
\text { well-being or rapport-building issues; } \\
\text { does not assume an abusive experience. }\end{array}$ & $\begin{array}{l}\text { So how are you doing today? } \\
\text { Tell me the things you like to do. } \\
\text { Tell me about your last birthday. }\end{array}$ \\
\hline $\begin{array}{l}\text { Open, abuse-related/ } \\
\text { Transitional question }\end{array}$ & $\begin{array}{l}\text { Open-ended inquiry that assumes } \\
\text { there may have been an } \\
\text { abusive experience. }\end{array}$ & $\begin{array}{l}\text { Tell me the reason we are talking today. } \\
\text { I understand something may have happened to } \\
\text { you. Tell me about it. }\end{array}$ \\
\hline $\begin{array}{l}\text { Invitation/Invitational } \\
\text { probe }\end{array}$ & Probe that invites a narrative. & $\begin{array}{l}\text { Tell me everything you can remember, from the } \\
\text { beginning, the middle, and end. } \\
\text { It is really important that I understand what } \\
\text { happened. Tell me about it. }\end{array}$ \\
\hline Follow-up strategies & $\begin{array}{l}\text { Strategies that encourage } \\
\text { continued narrative. }\end{array}$ & $\begin{array}{l}\text { Anything else you remember? } \\
\text { And then what happened? } \\
\text { Say more about that. }\end{array}$ \\
\hline Facilitative cue & $\begin{array}{l}\text { Interviewer gesture or utterance } \\
\text { aimed at encouraging more narration. }\end{array}$ & $\begin{array}{l}\text { Umhum. OK. } \\
\text { He touched you and then what? }\end{array}$ \\
\hline $\begin{array}{l}\text { Specific/Cued } \\
\text { invitations/Wh question }\end{array}$ & $\begin{array}{l}\text { Follow-up inquiry to gather details } \\
\text { about the child's experience. May be } \\
\text { a follow up on information } \\
\text { already reported. }\end{array}$ & $\begin{array}{l}\text { Where were you? } \\
\text { You said (event, action). Tell me more about that. } \\
\text { How old you were when the abuse started? }\end{array}$ \\
\hline Focused Question/Probe & $\begin{array}{l}\text { One that focuses the child on a } \\
\text { particular topic, place, or person, but } \\
\text { refrains from providing information } \\
\text { about the subject. }\end{array}$ & $\begin{array}{l}\text { Tell me about daycare. } \\
\text { Tell me about your dad. } \\
\text { What happens at bedtime? }\end{array}$ \\
\hline $\begin{array}{l}\text { Multiple choice/Option } \\
\text { posing question }\end{array}$ & $\begin{array}{l}\text { A question that presents the child } \\
\text { with a number of alternative } \\
\text { responses from which to choose. }\end{array}$ & $\begin{array}{l}\text { Did the abuse happen in the daytime or nighttime } \\
\text { or both? } \\
\text { Did he hurt you when you were in the bedroom, } \\
\text { kitchen, or some other room? }\end{array}$ \\
\hline $\begin{array}{l}\text { Externally derived } \\
\text { Question/Probe }\end{array}$ & $\begin{array}{l}\text { A question that relies on information } \\
\text { not disclosed in the child interview. }\end{array}$ & $\begin{array}{l}\text { I heard you talked to } \\
\text { Tell me what you talked about. } \\
\text { Your mom is worried about you. Tell me why. }\end{array}$ \\
\hline $\begin{array}{l}\text { Yes-no/Direct/Option } \\
\text { posing question }\end{array}$ & $\begin{array}{l}\text { A direct inquiry about a person or a } \\
\text { specific act. }\end{array}$ & $\begin{array}{l}\text { Did Mr. Jones touch do something he shouldn't have? } \\
\text { Did someone hurt your peepee? }\end{array}$ \\
\hline $\begin{array}{l}\text { Leading/Suggestive/ } \\
\text { Tag question }\end{array}$ & $\begin{array}{l}\text { A statement the child is asked } \\
\text { to affirm. }\end{array}$ & $\begin{array}{l}\text { Didn't Mr. Smith tell you not to tell anybody? } \\
\text { Your brother put his hand inside your pants, } \\
\text { didn't he? }\end{array}$ \\
\hline Coercion & $\begin{array}{l}\text { Use of inappropriate inducements to } \\
\text { get cooperation or information. }\end{array}$ & $\begin{array}{l}\text { You can have a break once you tell me about } \\
\text { the abuse. } \\
\text { When we're all done talking, we can go get some } \\
\text { ice cream. }\end{array}$ \\
\hline Close Ended & & Less Confidence \\
\hline
\end{tabular}


This Question/Probe Continuum is an attempt to capture the state of empirical knowledge and practice, but it does not include all the definitions and advice found in interview structures. Moreover, there remains disagreement about how egregious it is to employ more close-ended questions in a forensic interview. The reality is that protocols, such as the NICHD Protocol [27] to be described below, which strongly advises against close-ended questions, are able to reduce the number of close-ended questions, but not eliminate them. This dilemma derives not only from the predisposition of adults to ask close-ended questions when gathering information from children, something interview structures are intended to counter, but also from the children. Children may not have the capacity to report events to interviewers who are using open-ended probes, such as "tell me everything that happened from the beginning to the end." Moreover, they are likely to be reluctant to talk about their sexual abuse and, as a consequence, require more close-ended inquiry.

\section{Influential Interview Structures}

There is such a multiplicity of interview structures that they cannot all be described in this article. Interview structures that have had a marked impact on interview practice will be described. In addition, I have attempted to select interview structures that represent different approaches and are intended for different types of interviewers. Interview structures to be covered are the APSAC Practice Guidelines for Psychosocial Evaluation of Suspected Sexual Abuse, the Memorandum of Good Practice and its revision, Achieving the Best Evidence [59], RATAC [51], and the NICHD Protocol [27]. In a description of each protocol, I will note why it was selected.

\subsection{The APSAC Guidelines}

The APSAC Guidelines, Practice Guidelines for Psychosocial Evaluation of Suspected Sexual Abuse, were developed in 1990 by the American Professional Society on the Abuse of Children (APSAC) [65], were selected for inclusion because they were the first set of guidelines covering interview structure, captured best practice at the time, and are an example of flexible interviewing. Moreover, they influenced subsequent forensic interview structures. These guidelines were aimed at mental health professionals, as opposed to child protection and law enforcement professionals, and encompassed both forensic and non-forensic evaluations [65]. As already noted, the guidelines allow for a lot of flexibility. They do, however, state the evaluator must have a graduate level mental health degree and indicate a preference for the evaluator having three to five years of professional experience with sexually abused children. The APSAC guidelines are intended for professionals evaluating a spectrum of aspects of an allegation, not for professionals who are only conducting forensic interviews, and hence address issues beyond the child interview. These include advising that the evaluator gather information from collateral contacts, advising against using parent-child sessions to determine the likelihood of sexual abuse, stating that the evaluator need not interview the alleged offender to determine the likelihood of sexual abuse, and indicating that the evaluator may form an opinion about the likelihood of sexual abuse [65].

In terms of the child interview, the APSAC guidelines state that it is not necessary for the evaluator to have a written protocol, but advise providing the child with ground rules for the interview, exploring positive and neutral topics before asking about abuse, and using open-ended questions first in an attempt to elicit a narrative from the child. Further, these guidelines state that the evaluation should not be limited 
to a single child interview, support the use of media in the interview, including anatomical dolls, and recommend the evaluator consider multiple hypotheses that might explain the sexual abuse allegation [65]. These guidelines were revised in 1997 [66] and are currently under revision.

APSAC also has forensic guidelines for first responders and CAC interviewers, Forensic Interviewing in Cases of Suspected Child Abuse [67]. These practice guidelines are in their fourth edition.

\subsection{Memorandum of Good Practice \& Achieving the Best Evidence}

The Memorandum of Good Practice and its most recent version, Achieving the Best Evidence in Criminal Proceedings, will be described in this section. Although these interview structures were developed for law enforcement in England and Wales [59,68], they have been quite influential for the development of protocols in the United States. For example, the Memorandum of Good Practice was the first protocol to advise interviewers not to interrupt the child's narrative, as interviewers were prone to, to seek clarification. This instruction was incorporated into the NICHD Protocol, which is the model for many other protocols in both the United States and other countries. Another important instruction in the Memorandum and Achieving the Best Evidence is repeating the child's disclosures, using the child's own words. Although this instruction has not been as widely incorporated into other protocols, it is excellent advice. Using the child's own words avoids subtle distortions in the child's information.

\subsubsection{Memorandum of Good Practice}

The Memorandum of Good Practice was originally published in 1992, making it an early and therefore influential interview structure ${ }^{4}$. It is also probably the most widely known example of a flexible interview structure. Moreover, it is unique in that the Memorandum was developed to serve as a guide for law enforcement in England and Wales who were conducting interviews that were to be videotaped [68]. Policy in England and Wales differs substantially from that in the United States in that a videotaped statement from the child about his/her abuse can be entered into evidence in a criminal case in lieu of the child's in vivo testimony. Law enforcement also have the option of having the child produce a written statement to be used instead of live testimony. The Memorandum of Good Practice consists of four phases: (1) Rapport building; (2) Free narrative; (3) Gathering details; and (4) Closure, with additional specification about how to conduct each of these phases [68]. For example, as noted above, the Memorandum admonishes the interviewer not to interrupt the child and to allow for pauses, advice that law enforcement might especially need [68].

\subsubsection{Achieving the Best Evidence in Criminal Proceedings}

The Memorandum has been revised several times, and the current guide is entitled Achieving the Best Evidence in Criminal Proceedings and encompasses more than the child forensic interview [59]. It is a policy document developed to address all aspects of investigations involving sexually abused children and other vulnerable witnesses in England and Wales, and is 257 pages in length. Unlike interview structures in the U.S., which are not universal and vary depending upon the developer and by locality, Achieving

4 Thus, the Memorandum of Good Practice preceded the International Interdisciplinary Consensus Statement, which was first published in 1994. 
the Best Evidence is intended to be applied in all law enforcement investigations of sexual abuse cases in England and Wales ${ }^{5}$. The child forensic interview retains its flexible, four phased structure: (1) Establishing Rapport; (2) Free Narrative Account; (3) Questioning; and (4) Closing the Interview, but with greater emphasis on eliciting narrative accounts than found in the original Memorandum of Good Practice.

During Rapport, after identification of the parties present, time, and date for the video, the advice is to get the child to provide a narrative about neutral events (not positive ones), but not to allow this endeavor to go on too long out of concern the child will tire or will become confused about the purpose of the interview. Following this portion of the Rapport section, ground rules are provided. This interview structure does not include the permission to say "I don't know" rule. It does include the two "misunderstand" rules, "if you don't understand my question, tell me" and "if I misunderstand, tell me". Achieving the Best Evidence also includes the "ignorant interviewer" rule. Children are told that the interviewer wasn't there, does not know what happened, and needs details. Despite the fact that the video (or written statement) may be used at trial in place of the child's live testimony, interviewers are not to ask children to take an oath. The interviewer does, however, advise the child that it is important to tell the truth and may ask the child to give examples of truths and lies or provide examples for the child to identify as true or false. Witnesses are informed they can take a break anytime, and interviewers are advised that multiple breaks may be needed.

For the Free Narrative Account phase, this interview structure does not provide probes for transitioning to discussion of the abuse, but rather appears to assume the child will know why he/she is being interviewed. As in the Memorandum, interviewers are admonished not to interrupt the child. In terms of free narrative prompts, this interview structure specifies that they be open-ended and gives examples such as "anything else you remember". It also encourages active listening, that is, narrative cues as described in the Question/Probe Continuum.

The Questioning phase assumes the child has provided some narrative about abuse and is intended to gather additional information about the abusive incident and case-specific information, such as family composition and how the child knows the abuser. With questions about both the abuse and case, the interviewer is instructed to divide the topic and systematically explore, for example, everything about a specific abusive act. Appropriate questions include Open-ended, for example, "tell me more about..." and Specific-closed, which are questions about who, when, where, and what. Interviewers are instructed not to ask why questions and are advised to avoid Forced-choice questions (multiple choice and yes/no), asking Multiple questions in one query, and Leading questions.

During Closure, the interviewer summarizes the child's disclosure, using the child's own words, and invites correction and any additional information the child recalls. The interviewer then moves to a neutral topic, calms the child, if needed, and thanks the child $[59,68]$.

The Achieving the Best Evidence document provides flexibility and gives the interviewer autonomy to determine the most appropriate method for gathering information about abuse. It emphasizes that there is no single best interview structure. The document also makes specific reference to the Cognitive Interview [48] and the NICHD Protocol [27] as alternative interview structures for gathering information

5 Similarly, the NICHD Protocol applies to all interviews involving physical and sexual abuse allegations conducted by Israeli Youth Investigators. 
from the child. Achieving the Best Evidence also supports the use of dolls, including anatomical dolls, drawings, and other props, and provides appropriate guidance on their use and cautionary advice [69].

\subsection{The CornerHouse Forensic Interview Protocol: RATAC}

RATAC stands for: (1) Rapport; (2) Anatomy Identification; (3) Touch Inquiry; (4) Abuse Scenario; and (5) Closure. The RATAC interview structure has been very influential because, in 2002, it was incorporated into the Finding Words training curriculum, sponsored by the American Prosecutors Research Institute and provided by the National Center for the Prosecution of Child Abuse [70,71]. In addition, in 2007, the National Child Protection Training Center, founded by Victor Vieth, entered into a contract with CornerHouse to continue to develop and sustain state courses using the RATAC protocol [71]. As will be discussed below, RATAC and its various iterations are among the most widely trained interview structures in the United States. Although there have been recent changes in the RATAC protocol in response to CornerHouse and other research, because so many professionals were trained on the original RATAC protocol and continue to follow its guidance, it is important to describe the original protocol. Revisions of RATAC will be described in subsequent sections.

The RATAC protocol is semi-structured, meaning that the interviewer makes choices about the use of components in the structure. It shares commonalities with other interview structures, but also is distinct [72]. The distinctions will be described in the next sub-sections.

\subsubsection{Interview Ground Rules}

Unlike other interview structures, RATAC, in its original form, did not give the child the ground rules at the beginning of the interview, but rather incorporated them as the need arose during the interview. The designers of RATAC decided that giving the children a list of rules at the beginning was too authoritarian and created a negative tone [51]. They acknowledged, however, that teaching interviewers the skill of knowing when to provide a rule was more challenging than providing all the rules at the beginning of the interview [73].

\subsubsection{Use of Media}

RATAC also makes considerable use of media [51,74]. There is an easel with newsprint, which is shared drawing and writing space for both the interviewer and the child. The interviewer may use a number of drawing tasks. During Rapport, the interviewer may draw a face picture of the child, sometimes with the child's help, and employ "family circles", ovals with eyes and a smile, which can be used to designate the people with whom the child lives. When the interviewer engages the child in Anatomy Identification, the interviewer employs anatomical drawings, selecting both male and female drawings that reflect the child's ethnicity. Anatomical drawings are also used during the Touch Inquiry phase to first identify positive touches (e.g., kisses, hugs) and then negative touches (e.g., places no one is supposed to touch) [74]. During the Abuse Scenario phase, the interviewer may use anatomical dolls to gather information about sexual abuse after the child has indicated something of an abusive nature happened $[73,74]$. 


\subsubsection{Questioning Strategies}

The original RATAC questioning strategy also differed from strategies in many other interview structures $[74,75]$. It did not rely on a strict hierarchy of most preferred (open-ended) to least preferred (close-ended) questions. Other interview structures rely heavily on invitational probes (e.g., "Tell me the reason you are here" "Tell me all about that") to elicit narrative accounts from children. The RATAC designers viewed invitational questions as not developmentally appropriate for younger children and preferred focused questions (e.g., "Where on your body were you touched?").

RATAC traditionally relied on the use of a yes/no question to introduce a topic of concern (e.g., "Are there places on your body no one should touch?"). This is known as scaffolding [75] and alerts the child to the topic to be discussed. If the child responds positively, then the interviewer would follow with "wh" questions. These would be followed by a close-ended question. For example, if the child answered yes to the yes/no question about inappropriate body touch, the interviewer would ask, "where?" The interviewer could then ask, "Has someone touched you in one of those places?"

The RATAC protocol also included invitational probes, but they were not the first abuse-related questions. The Touch Inquiry, which relies for the most part on yes/no and focused questions, was the transition to the abuse-related part of the interview. That said, one of the alternative strategies for the Touch Inquiry is the invitational question, "What do you know about coming to talk to me today?" [74].

\subsubsection{The Revision of the CornerHouse Protocol}

In 2013, subsequent to research conducted at CornerHouse [76] and likely some challenges to their use of media and questioning strategies, CornerHouse substantially revised their interview structure [76,77]. Added components are "orienting messages", that is interview ground rules, the use of a narrative approach, and privileging an invitation to children of all ages to tell what they know about the interview and its purpose [78]. The CornerHouse current structure is: (1) Build Rapport; (2) Seek Information; (3) Explore Statements; and (4) End Respectfully. It employs narrative practice during the Build Rapport stage and includes invitation and encouraging a narrative during the Explore Statements phase [77,78]. It does not abandon its use of media, but their use is not so prominently featured in the interview structure. Despite the revisions, the protocol remains faithful to CornerHouse's "Child First Philosophy", which is its hallmark [78]. See also the First Witness Protocol, developed by the CAC in Duluth, Minnesota. First Witness is a modified RATAC interview structure based upon the CornerHouse research on narrative practice [79].

\subsubsection{The ChildFirst Protocol}

Just as CornerHouse revised its protocol, so did the National Child Protection Training Center, now called the Gundersen National Child Protection Training Center, with whom CornerHouse partnered in training. This new protocol takes into account the changes in CornerHouse Protocol, but also is based upon a review of existing protocols and training in forensic interviewing. The ChildFirst Protocol is a four phase structure: (1) Rapport; (2) Transition to the Topic of Concern; (3) Explore Details; and (4) Closure [80]. Narrative practice is an important technique during Rapport. Narratives are also encouraged during later phases of the interview structure. 
The Rapport stage differentiates strategies by the child's age, under 5, 6-10, 11 and up. The five and under children are not informed of the fact they are being video-taped and that people are watching the interview, but older children are. With the five and under group, the interviewer uses the face drawing of the child and the family drawing, as found in RATAC. With older children these activities are optional, and the face drawing is not used with the oldest group. For all age groups, interviewers can choose whether or not to engage in a discussion of the truth/lie and request that the child promise to tell the truth [80].

The ChildFirst Protocol also takes into account relatively new knowledge about polyvictimization [81]. Children who experience sexual abuse are at greater risk for other types of victimization [81]. Interviewers inquire about a spectrum of types of maltreatment. [80]. In summary, despite the fact that National Child Protection Training Center has given their protocol a new name, ChildFirst, and has considered other forensic interview protocols, it retains many commonalities with the RATAC and revised CornerHouse Protocols.

\subsection{The NICHD Protocol}

Arguably, the most important development in forensic interviewing during the last 40 years has been the development of the NICHD Forensic Interview Protocol [27]. Michael Lamb and Kathleen Sternberg, two eminent developmental psychologists who worked for the U.S. National Institute of Health and Human Development, spear-headed the development of the NICHD Protocol. Their goals were to enhance the competence of interviewers and to enhance the ability of children to provide accurate and coherent accounts of their experiences. Reasons for the marked impact of the NICHD Protocol will be described in the next subsection. This will be followed by a description of the protocol, a discussion of distinguishing features of the NICHD Protocol, its revision, and its impact on other protocols.

\subsubsection{Reasons the NICHD Protocol Has Had Such a Marked Impact}

There are at least three reasons that the NICHD Protocol is the most important development in forensic interviewing. First, the NICHD team developed collaborations in other developed countries, notably Israel, Great Britain, Scotland, Canada (Quebec), and Sweden [82,83]. As a consequence the NICHD team has access to interview data on over 40,000 forensic interviews using the NICHD Protocol and can conduct research on these cases [84]. Perhaps most significant is their collaboration in Israel. Israeli Youth Investigators, who conduct forensic interviews on all cases involving physical and sexual abuse, use the NICHD Protocol. Moreover, the Israeli Ministry of Labour and Social Affairs supports data collection. The NICHD Protocol has been translated into the following languages: Chinese, Finish (adapted version), French (Canada), Georgian, Hebrew, Italian, Japanese, Portuguese, and Spanish [83]. All language versions are available on the website [83].

Second, these partnerships enabled field research, as opposed to laboratory research on interview practices. Although laboratory or analogue studies ${ }^{6}$ play a role in understanding how children report their experiences, these studies cannot replicate in their research designs the trauma, secrecy, and stigma

6 These studies involve children, primarily non-abused children, who experience events that are intended to be analogous to sexual abuse (e.g., activities involving body touch) and are asked to report these events in interviews that intend to replicate forensic interviews. 
associated with sexual abuse. The studies also do not reflect the challenges experienced in the field by actual forensic interviewers.

Third, the NICHD team had access to the infrastructure to study the effects of interview practices. Although administrative data are useful in evaluating interview outcomes (e.g., percent of disclosures, court outcomes), determining the utility of specific interview practices is very labor intensive. It requires recording and transcribing interviews, developing coding systems for interviewer utterances and child responses, and having the staff resources to code and analyze interview data. It also requires professionals who are motivated to write articles and books for professional consumption. To date, there are approximately 100 articles and five books describing research on the NICHD Protocol [84]. Thus, the research on the NICHD Protocol is very impressive and cannot be rivaled by research on other interview structures. Indeed, many other protocols have relied on the NICHD research and incorporated components of the NICHD Protocol into their interview structures (e.g., Ten Step Investigative Interview Protocol [49], RADAR [57], Michigan Forensic Interview Protocol [53]).

\subsubsection{Description of the NICHD Protocol}

The NICHD Protocol took as its starting point knowledge of child development; thus, it is built upon research conducted on normal children. The NICHD Protocol is an 11 or 12 phase protocol (the researchers are involved in ongoing efforts to improve the Protocol, based upon input from those using it and upon research findings). The phases are: (1) Introduction, during which the interviewer describes his/her role and provides ground rules for the forensic interview; (2) Rapport Building, which includes asking the child about things he/she likes to do; (3) Training in Episodic Memory, which involves asking about a recent event salient to the child and/or about everything that happened yesterday or today; (4) Transition to Substantive Issues (e.g., sexual abuse concerns); the Protocol provides nine different probes, from open-ended to more close-ended to assist the interviewer and the child in this transition; (5) Investigating the Incidents, using repeated invitational probes (e.g., "tell me everything about that", "tell me more", "and then what happened"); (6) Break, during which the interviewer leaves the room and formulates focused question as needed to gather additional details; (7) Eliciting Information that has not been mentioned by the child; these are the "who, what, when, and where" questions; (8) If the Child Fails to Mention Information you expected; during this phase, the interviewer uses externally derived information (e.g., a prior disclosure) in focused questions to elicit a disclosure or additional information; (9) Information about the Disclosure, queries about whether the child has told someone before coming to the forensic interview and the response of the person; (10) Closing, during which the interviewer asks if there is anything else the child has to tell and if the child has questions of the interviewer; and (11) Neutral Topic; the interviewer might ask the child what he/she will do after the child leaves [27,85]. As will be described in the next sections, the NICHD Protocol has a number of distinguishing characteristics.

\subsubsection{The Importance of Narrative Accounts}

At the core of the NICHD Protocol is eliciting a narrative account from the child. Although other interview structures advise strategies for eliciting narratives, NICHD has really led the field in its insistence on techniques to produce narratives. Narrative accounts are more accurate than responses to more close-ended inquiry, for example yes/no questions. 
The Rapport building and Training in Episodic Memory phases are intended to "teach" the child to respond with a narrative so that this skill will be reflected in the child's description of the abuse. Early research by the NICHD team compared the typical rapport-building strategy, which consisted of short answer questions (e.g., where do you go to school? what grade are you in? what is the name of your teacher? and do you like school?) to rapport-building using invitational probes (e.g., tell me all about school, tell me all about a recent holiday) [86]. This study demonstrated that not only did the invitational probes result in longer narratives during rapport building but also during the responses to the invitation about abuse, "I understand something may have happened to you. Tell me about it from the beginning to the end." Interviewers in both conditions used this invitation.

\subsubsection{Transitional Probes}

Because professionals in the field were concerned that probes, such as "tell me the reason you are here" weren't sufficiently focused, Lamb and colleagues developed a total on nine transitional probes. Later versions of the NICHD Protocol used a different initial invitational probe from the one used in their 1997 research. The current probe is "Now that I know you a little better, tell me the reason you are here" [27]. This first probe now precedes the "I understand something may have happened to you..." probe, as the former is considered more open-ended. Other probes include asking the child why the transporter (mom, worker) brought the child, referencing prior disclosures, and querying whether someone is worried about the child. All probes are posed in as open-ended a manner as possible so as not to be suggestive of the specifics of the alleged abuse. The NICHD research, however, has demonstrated that, for children who disclosed, they usually did so to the first or second probe [87].

\subsubsection{Taking a Break before Focused Questions}

Other interview structures include a break after the interviewer has asked about abuse, during which the interviewer goes into the room where other professionals are observing. The primary purpose of the break is to obtain input about what other questions to ask, for example from the prosecutor. The NICHD Protocol break has an additional purpose, which is to assure that the interviewer is mindful as he/she moves into more close-ended questions and probes and plans these questions carefully [27].

\subsubsection{Use of Media}

The NICHD Protocol does not support the use of media, such as drawings or dolls, to gather information about abuse. One rationale for this is that inviting narratives accesses free recall memory, whereas media, such as anatomical dolls and drawings, rely upon recognition memory. Free recall is the more accurate than recognition memory, although often less detailed [88]. Secondly, children younger than three and a half may not be able to make the representational shift involved in having a doll or drawing represent a person [28,58]. Moreover, Lamb and colleagues point out that some analogue research demonstrates that anatomical dolls can elicit high rates of both false positives and false negatives with very young children $[89,90]$. Finally, Lamb and colleagues co-authored two studies that failed to find "value added" (that dolls elicited more information than verbal inquiry alone) in field interviews using anatomical dolls [91,92]. 
Nevertheless, the NICHD Protocol researchers have engaged in field research that has demonstrated the "value added" of a human figure drawing [93] and of asking the child to draw a picture of the abuse [94]. In both of these studies, the drawing activity was introduced after verbal inquiry and elicited substantial portions of new information.

\subsubsection{The Revised NICHD Protocol}

The initial focus of the NICHD Protocol was on children who disclosed sexual abuse during the forensic interview. Overall this was more than two-thirds of children interviewed [5]. Some years ago, relying primarily on the data from Israeli Youth Investigator interviews, Lamb and colleagues began to turn their attention to children who did not disclose during a single forensic interview. Examining the dynamics of interviews in high certainty cases (cases with substantial corroborating evidence) where children did and did not disclose sexual abuse, they noted that non-disclosing children were non-communicative beginning during the rapport-building phase of the interview, and interviewers were correspondingly less supportive of these children. These dynamics carried over into the abuse-related phases of the interviews [95]. They made two recommendations based upon these findings: (1) when interviewers find children not forthcoming during rapport-building, they should extend rapport-building rather than moving on to the abuse-related phases of the interview; and (2) interviewers should consider a second interview [95].

More recently, the NICHD researchers have revised their protocol to make it more child friendly $[96,97]$. The revised protocol changes the order of ground rules and rapport by placing building rapport before providing interview rules. Thus, after introducing him/herself and noting that the interview will be recorded, the interviewer asks the child about things he/she likes to do, seeking narratives from the child. After that, the interview ground rules are provided.

Hallmarks of the Revised NICHD protocol are instructing the interviewer to present a friendly, supportive demeanor, to use the child's name frequently during the interview, to acknowledge the child's feelings, but not to interpret them, and to provide non-contingent positive reinforcement. With regard to demeanor, Lamb and colleagues encourage smiling, leaning forward, and making eye contact. In the Revised NICHD protocol, interviewers can acknowledge the child's feeling related to the interview process. The interviewer can say, for example, "I see you are upset". The interviewer may also say, "You are really doing a good job", but take care not to provide this feedback only when the child discloses abuse [97,98].

To date, there are two published studies comparing the Revised NICHD Protocol to the Standard NICHD Protocol. Because there is substantial research documenting lower disclosure rates in intra-familial sexual abuse, these two studies involved allegations of intra-familial abuse. Both studies demonstrate increased disclosure rates using the Revised NICHD Protocol when compared to the Standard NICHD Protocol [97,98].

\subsubsection{The Influence of the NICHD Protocol on Other Forensic Interview Protocols}

Many interview structures have adapted or adopted all or substantial portions of the NICHD Protocol [99]. For example, many interview structures have adopted as a whole or in part the NICHD transitional probes. Similarly, most protocols now emphasize the importance of narrative accounts of 
abuse. Two interview structures are described as adaptations of the NICHD Protocol, but also have their own distinctive features. These are the Ten Step Investigative Interview Protocol [49] and RADAR [57].

The Ten Step Investigative Interview Protocol is labeled as an adaptation of the NICHD Protocol [49]. The Ten Step is much more succinct; it is only two pages, as compared the NICHD's 13 pages. The Ten Step only covers the allegation portion of the interview and not the rapport-building and the closure portions. It has the advantage over the NICHD of being quite user friendly. It is formatted so that the 10 steps have brief headings in larger font, followed by actual probes in smaller font. Because it is only two pages, it can easily be brought into the interview room.

RADAR (Recognizing Abuse Disclosure types and Responding) [57] is an interview structure that is described as adapted, in part, from the NICHD Protocol. It appears to have taken portions from both the Revised NICHD Protocol (placing the rapport-building before the ground rules) and from the Standard NICHD Protocol (e.g., narrative practice and the transition probes, although the latter are used later in the interview). RADAR also has elements not found in other interview structures. At the end of Rapport, the child is given an opportunity to ask the interviewer questions. Other interview structures may include such an opportunity during closure (e.g., NICHD [27]). In RADAR, after the ground rules phase, the interviewer conducts a barrier assessment. This begins with the interviewer asking the child how he/she feels about talking to the interviewer, followed by a query about whether the child is worried about talking. Whether or not the child acknowledges worries, the interview then asks the "try your best while we talk". RADAR also differentiates interview instructions based upon the child's age, something the NICHD does not do (but RATAC [51] and ChildFirst [55] do). Finally, RADAR includes instructions about when to interview the child a second time and when to recommend an extended assessment [57].

State forensic interview protocols have also been highly influenced by the NICHD Protocol and its research. Among these are the Washington State [54] and the Michigan [53] protocols.

\section{Training for Forensic Interviewers}

Specialized training programs have been developed for forensic interviewers. These programs are needed for professionals with graduate mental health training, for CAC forensic interviewers, and for mandated child protection and law enforcement personnel who conduct forensic interviews. Mental health professionals are not usually taught forensic interview practices during their graduate training; indeed, they may need forensic interview training to "unlearn" the therapeutic interview skills taught in graduate and professionals schools [99]. In contrast, mandated investigators may be starting from scratch because often they have no training in child development, in children's memory and suggestibility, or in talking to children. Moreover, most of these professionals need training in defending their interviews in court.

\subsection{Typical Training Programs and Topics}

Currently, forensic interview training programs range from two days [100] to 40 hours (one week) [101]. These are sponsored by state agencies responsible for training child protection and law enforcement [100], professional organizations (e.g., APSAC [101]), and agencies responsible for interviewing children (e.g., National Children's Advocacy Center [102], CornerHouse [103], First Witness [104]). These forensic interview training programs are often specific to a particular interview structure or protocol (e.g., NICHD [27], RADAR [57]). They also usually include information on child development and 
children's memory and suggestibility. Many include opportunities to conduct practice interviews of real children, of actors playing the roles of abused children, or of colleagues who are also participants in the interview training. These interviews may be critiqued by the trainers and other interview experts. Some of the longer training programs provide an opportunity for trainees to defend their mock interviews in a mock court (e.g., APSAC Forensic Interview Clinic [101]).

In addition to basic forensic interview training, there are also a number of agencies and states that provide advanced training. Topics for advanced training for forensic interviewers include: (1) Interviewing reluctant children; (2) Interviewing special needs children; (3) Interviewing sexually exploited children, (4) Interviewing pre-school children; and (5) Forensic interviewing for Spanish-speaking children (e.g., Gunderson National Child Protection Training Center [105]; National Children's Advocacy Center [102]).

\subsection{Statistics on Training Programs}

According to a 2013 survey with responses from 320 of the 916 CACs from which data were solicited, the training program most commonly attended was NCAC/Huntsville training (42\%), followed closely by the Finding Words/ChildFirst training (39\%). Thirty-two percent attended the CornerHouse Forensic Interview training and $31 \%$ the RATAC training; when combined they constituted $63 \%$ of training programs attended. Fourteen percent of respondents' staff attended an APSAC forensic interview clinic, $35 \%$ state-based training, $10 \%$ the NICHD training, and 8\% other trainings [106]. The National Children's Advocacy Center conducted a survey of 247 CAC respondents in 2009 with similar results [107].

More than 54,000 child abuse professionals from all 50 states and 20 countries have been trained by the NCAC [34]. CornerHouse has provided forensic interview training to over 29,000 professionals from every state in the United States and in 18 foreign countries, including the investigators of the International Criminal Court at the Hague [103]. Children's Advocacy Center interviewers and mental health professionals who engage in forensic interviewing are likely to attend training on a number of interview structures and to continue to develop their skills by attending advanced training [106,107]. Despite the modest percentage of participants who have attended training on the NICHD protocol in the U.S., training in other countries is le, extensive. For example, all forensic interviewers in Israel are trained on the NICHD protocol [5].

\subsection{Implementing Training in Forensic Interview Practice}

Despite training, research on the NICHD and other protocols indicates that it is difficult for forensic interviewers to follow the advice of forensic interview trainers and to adhere to interview structures [108]. Professionals may think they are actually following the interview guidelines, but analysis of their interviews indicates that they are not [109,110]. Although forensic interviewers have been faulted for failure to follow forensic interview structures, it is important to acknowledge that they are also admonished to follow the child. They often face the dilemma of "follow the protocol or follow the child", a dilemma exacerbated by the fact the child is unfamiliar with the protocol [46].

Various strategies have developed to assist interviewers in adhering to interview structures. One is “quick guides" (Michigan [53], Washington State [54]). These are short summaries on laminated cards of the procedures for various components of the interview, for example, of transition probes and appropriate questions. The interviewer has these in the interview room and can refer to them. RADAR is actually 
incorporated into a laminated pocket guide, which is 12 double-sided 4 by 6 inch pages, with color-coded tabs so the interviewer can quickly find the appropriate section [57].

A second strategy is ongoing (weekly) supervisor feedback on adherence to the interview structure. This is labor intensive because it requires the supervisor to review a video or transcript of the interview [109-111]. Research indicates that supervisor feedback is effective, but it needs to be ongoing. Otherwise, interviewers begin to deviate from the interview structure.

A third strategy is peer review. In the national survey of U.S. CACs conducted by the National Children's Advocacy Center in 2009, 94\% of respondents stated they participated in peer review [107]. Peer review, however, is usually not weekly, as recommended by Lamb and colleagues [111]. Rather it is most likely to be quarterly. Such peer review usually involves forensic interviewers bringing challenging cases and asking for advice from peers. Peer review does not necessarily address adherence to a forensic interview protocol.

\section{Conclusions}

Forensic interviewing to determine the Likelihood of child sexual abuse is a dynamic and evolving area of practice. This review has documented the remarkable progress over the last 40 years. The dynamic nature of the field is demonstrated in the constant changes and improvement in forensic interview models and structures. Especially helpful in the progress has been the research of the team advocating the NICHD Protocol [27,82,84-87,93-98].

Nevertheless, forensic interviewing continues to be characterized by a number of contested issues. These include: (1) Whether an interview structure should flexible, semi-structured, or scripted; (2) Whether, which, and how ground rules should be introduced; (3) Whether children need to complete the truth/lie exercise; (4) What the most appropriate types of questions are; (5) The relative importance of eliciting narratives; (6) Whether media should be employed in forensic interviews; and (7) Whether children should be allowed more than one interview. Moreover, the forensic interview field is still struggling with how to ensure that interviewers actually implement the training they have received and follow interview structures.

Much of the research and the practice advice has been driven by the concern that forensic interview practices might elicit false reports of sexual abuse and thereby jeopardize the lives of adults. More recently there is an appreciation that the single forensic interview, limited to open-ended questions, may jeopardize the lives of children, who are fearful of disclosing their abuse. Developing a balance between interview strategies that correctly identify sexually abused children (sensitivity) and correctly exclude children who have not been sexually abused (specificity) is enormously challenging, and the stakes are high.

There is much work to be done. Models that allow the child more than one chance to tell must be a future focus, that is, providing for more than a single interview and extended assessment for children, who are reluctant, frightened, or compromised in other ways, so they can experience safety and justice. Work is emerging that acknowledges this need [112-115].

In addition, although gender differences in both interviewers and children have received attention [116], racial and ethnic differences have hardly been studied [116,117]. There is some training for forensic interviewers who need to interview children in Spanish, but racial and ethnic issues have not been sufficiently addressed. For example, despite the fact that Israeli Youth Investigators are interviewing 
both Jewish and Arab children (both populations in Hebrew), the researchers have not examined how ethnicity may affect the disclosure rates.

The challenge of interviewing very young children remains. Their assessment needs have been addressed in the clinical literature [29], but they remain a highly vulnerable population. As noted earlier [28,88], children four and older have been successfully forensically interviewed, but the three and younger population cannot be reached with current forensic interview structures $[29,30]$.

Finally, what has been learned by conducting forensic interviews of children who may have been sexually abused in the United States and other developed countries needs to lead to comparable applications in other countries. Arguably the problem of sexual abuse is as great or greater in the developing world [118]. Children in these countries deserve protection and justice, too.

Despite the work that remains, the development of forensic interviews for children alleged to have been sexually abuse is quite remarkable. This approach has inspired a new professional role, the forensic interviewer. Forensic interviews originated as a strategy to address the problem of sexual abuse. These interviews are now being employed to elicit disclosures of other types of maltreatment and endangerment of children $[5,55]$.

\section{Conflicts of interest}

The author declares no conflict of interest.

\section{References}

1. Henry, Kempe C. "Sexual abuse: Another hidden problem." Pediatrics 62 (1978): 382-89.

2. Finkelhor, David. Sexually Victimized Children. New York: The Free Press, 1979.

3. Finkelhor, David. "Chapter 1: Sexual abuse as a social problem." In Child Sexual Abuse: New Theory and Research. Edited by David Finkelhor. New York: The Free Press, 1984, pp. 1-13.

4. Jones, David, and Mary McQuiston. Interviewing the Sexually Abused Child. Denver: Kempe National Center for the Prevention and Treatment of Child Abuse, 1986.

5. Hershkowitz, Irit, Dvora Horowtiz, and Michael Lamb. "Trends in children's disclosure of abuse in Israel: A national study." Child Abuse \& Neglect 29 (2005): 1203-14.

6. Olafson, Erna, David L. Corwin, and Roland C. Summit. "Modern history of child sexual abuse awareness: Cycles of discovery and suppression." Child Abuse \& Neglect 17 (1993): 7-24.

7. Faller, Kathleen Coulborn. Child Sexual Abuse: Intervention and Treatment Issues. Washington, D.C.: U.S. Department of Health and Human Services, 1993.

8. Everson, Mark. "Child Forensic Interviewing at Age 30: Virtuous to a Fault." Paper presented at the San Diego International Conference on Child and Family Maltreatment, San Diego, CA, USA, 26 January 2012.

9. Ceci, Stephen, and Maggie Bruck. Jeopardy in the Courtroom. Washington, D.C.: American Psychological Association, 1995.

10. Hechler, David. The Battle and the Backlash: The Child Sexual Abuse War. Lexington: Lexington Books, 1989.

11. Myers, John E. B. The Backlash: Child Protection under Fire. Thousand Oaks: Sage Publications, 1994. 
12. Finkelhor, David, Linda Williams, and Nancy Burns. Nursery Crimes: Sexual Abuse in Day Care. Newbury Park: Sage Publications, 1988.

13. Butler, Edgar, Hiroshi Fukurai, Jo-Ellen Dimitrius, and Richard Krooth. Anatomy of the McMartin Child Molestation Case. Lanham: University Press of America, 2001.

14. Richardson, Sue, and Heather Bacon. Child Sexual Abuse: Whose Problem? Reflections from Cleveland. Edited by Sue Richardson and Heather Bacon. Birmingham: Venture Press, 1991.

15. Gall, Charlie. "Orkney Child Sex Abuse Scandal: 20 Years since the Ordeal that Horrified a Nation." Daily Record. Available Online: http://www.dailyrecord.co.uk/news/real-life/orkneychild-sex-abuse-scandal-1099361 (accessed on 10 June 2014).

16. Cheit, Ross. The Witch-Hunt Narrative: Politics, Psychology, and the Sexual Abuse of Children. New York: Oxford University Press, 2014.

17. "Child Abuse Prevention and Treatment Act. CAPTA Reauthorization Act of 2010 (P.L. 111-320)." Child Welfare Information Gateway, 2011. Available online: https://www.childwelfare.gov /systemwide/laws_policies/federal/index.cfm?event=federalLegislation.viewLegis\&id=142 (accessed on 1 June 2014).

18. American Humane Association. Official Reports of Child Abuse and Neglect 1978. Denver: American Humane Association, 1980.

19. U.S. Department of Health and Human Services, Administration for Children and Families. "Child Maltreatment 2012." Available online: http://www.acf.hhs.gov/programs/cb/resource/childmaltreatment-2012 (accessed on 2 June 2014).

20. Nelson, Barbara. Making and Issue of Child Abuse. Chicago: University of Chicago Press, 1984.

21. Faller, Kathleen Coulborn. "Interviewing children who may have been abused: A historical perspective and overview of controversies." Child Maltreatment 1 (1996): 4-18.

22. Alexander, Randell A. "Medical advances in child sexual abuse." Journal of Child Sexual Abuse: Research, Treatment, \& Program Innovations for Victims, Survivors, \& Offenders 20 (2011): 481-85.

23. Faller, Kathleen Coulborn. "Chapter 5: Child Interviews When Sexual Abuse is Suspected." In Understanding and Assessing Child Sexual Maltreatment. Thousand Oaks: Sage Publications, 2003, pp. 105-40.

24. Faller, Kathleen Coulborn. "Chapter 1: Child Maltreatment and Child Protection in the United States." In Maltreatment in Early Childhood: Tools for Research-Based Intervention. Edited by Kathleen Coulborn Faller. New York: Haworth Press, 2000, pp. 1-12.

25. Scheuer, Suzanne. Michigan State University, East Lansing, MI, USA. Personal communication, 20 May 1980.

26. State of Michigan Child Protection Law. Act No. 238, Public Acts of 1975, as Amended, Being Sections 722.621-722.638, Michigan Compiled Laws. Michigan: State of Michigan Child Protection Law, 2011.

27. Lamb, Michael, Yael Orbach, Irit Hershkowitz, Phillip Esplin, and Dvora Horowitz. "A structured forensic interview protocol improves the quality and informativeness of investigative interviews with children: A review of research using the NICHD Investigative Interview Protocol." Child Abuse \& Neglect 31 (2007): 1201-31. doi:10.1016/j.chiabu.2007.03.021.

28. DeLoache, Judy, and Diane Marzolf. "The use of dolls to interview young children: Issues of symbolic representation.” Journal of Experimental Clinical Psychology 60 (1995): 155-73. 
29. Hewitt, Sandra. Assessing Allegations of Sexual Abuse in Preschool Children: Listening to Small Voices. Thousand Oaks: Sage Publications, 1999.

30. Faller, Kathleen Coulborn, and Sandra Hewitt. "Chapter 10: Special Considerations for Cases Involving Young Children." In Interviewing Children about Sexual Abuse: Controversies and Best Practice. Edited by Kathleen Coulborn Faller. New York: Oxford University Press, 2007, pp. 142-51.

31. Bolen, Rebecca. "Chapter 6: Extra-familial Sexual Abuse." In Child Sexual Abuse: Its Scope and Our Failure. New York: Kluwer Academic/Plenum Publishers, 2001, pp. 91-112.

32. Faller, Kathleen Coulborn. "Chapter 3: Working with Protective Services and the Police." In Understanding and Assessing Child Sexual Maltreatment, 2nd ed. Thousand Oaks: SAGE Publications, 2003, pp. 55-72.

33. National Center for the Prosecution of Child Abuse. Child Abuse and Neglect State Statute Series: Vol. 5. Crimes. Washington, D.C.: National Center on Child Abuse and Neglect Clearinghouse, 1997.

34. National Children's Advocacy Center. "History." Available online: http://www.nationalcac.org/ history/history.html\# (accessed on 20 June 2014).

35. Cordisco-Steele, Linda. National Children's Advocacy Center, Huntsville, AL, USA. Email communication, 2 October 2014.

36. National Children's Advocacy Center. "About the NCAC Child Abuse Library Online (CALiO)." Available online: http://www.nationalcac.org/calio-library/about-the-ncac-child-abuse-reseachlibrary-calio.html (accessed on 3 October 2014).

37. National Children's Advocacy Center. Available online: http://www.nationalcac.org/history/ history.html (accessed on 3 October 2014).

38. National Children's Alliance. "Standards for Accredited Members Revised 2011." Available online: http://www.nationalchildrensalliance.org/sites/default/files/download-files/NCARevised StandardsforMembers_0.pdf (accessed on 3 October 2014).

39. CornerHouse. "Timeline." Available online: http://www.cornerhousemn.org/timeline.html (accessed on 14 June 2014).

40. Jones, David, and Mary McQuiston. Interviewing the Sexually Abused Child. London: Gaskell Royal College of Psychiatrists, 1989.

41. Idaho V Wright 116 Idaho 382, 775 P-2d 1224 (1989).

42. Conte, Jon, Erin Sorenson, Linda Fogarty, and Julie Dalla Rosa. "Evaluating Children's Reports of Sexual Abuse: Results from a Survey of Professionals." American Journal of Orthopsychiatry 61 (1991): 428-37.

43. Child Welfare Information Gateway. "The Child Abuse and Neglect User Manual Series." Available online: https://www.childwelfare.gov/pubs/usermanual.cfm (accessed on 1 June 2014).

44. Lamb, Michael. "The Investigation of Child Sexual Abuse: An International, Interdisciplinary Consensus Statement." Family Law Quarterly 28 (1994): 1021-28.

45. Faller, Kathleen Coulborn, Marguerite Grabarek, and Robert Ortega. "Commitment to Child Welfare Work: What Predicts Leaving and Staying?" Children and Youth Services Review 32 (2010): 840-46.

46. Faller, Kathleen Coulborn. "Chapter 7: Interview Structure, Guidelines, and Protocol." In Interviewing Children about Sexual Abuse: Controversies and Best Practice. New York: Oxford University Press, 2007, pp. 66-89. 
47. Yuille, John. The Step-Wise Interview: Guidelines for Interviewing Children. Edited by John C. Yuille. Kelowna: Department of Psychology, University of British Colombia, 2002.

48. Saywitz, Karen R., Edward Geiselman, and Gail Bornstein. "The Effects of Cognitive Interviewing and Practice on Children's Recall Performance.” Journal of Applied Psychology 77 (1992): 744-56.

49. Lyon, Thomas. "The Ten Step Investigative Interview, 2nd ed." Available Online: http://works.bepress.com/thomaslyon/5/ (accessed on 14 October 2005).

50. National Children's Advocacy Center. "Update to National Children's Advocacy Center's Forensic Interview Structure 2014.” Available online: http://www.nationalcac.org/images/pdfs/ TrainingandConferences/NCAC-Training/ForensicInterviewingOfChildren/TrainingMaterialsBFI/2014TrainingMaterials/Update\%20to\%20NCAC\%20CFIS\%20-3-4-14.pdf (accessed on 10 December 2014).

51. Anderson, Jennifer, Julie Ellefson, Jodi Lashley, Anne Lukas Miller, Sara Olinger, Amy Russell, Julie Stauffer, and Judy Weigman. "The Cornerhouse Forensic Interview Protocol: RATAC®.” $W$. M. Cooley Journal of Practice and Clinical Law 1 (2010): 193-331.

52. Oregon Department of Justice, Crime Victims' Services Division, Child Abuse Multidisciplinary Intervention (CAMI) Program. “Oregon Interviewing Guidelines, Third Edition, 2012.” Available online: http://www.doj.state.or.us/victims/pdf/oregon_interviewing_guidelines.pdf (accessed on 10 July 2014).

53. State of Michigan Governor's Task Force on Child Abuse and Neglect and Department of Human Services. "Forensic Interviewing Protocol, 3rd ed." Available online: http://www.michigan.gov/ documents/dhs/DHS-PUB-0779_211637_7.pdf (accessed on 10 July 2014).

54. Harborview Center for Sexual Assault and Traumatic Stress, and WA State Criminal Justice Training Commission. "Washington State Child Interview Guide." Available online: http://depts.washington.edu/hcsats/PDF/guidelines/WA\%20State\%20Child\%20Interview\%20Gui de\%202009\%202010.pdf (accessed on 10 July 2014).

55. National Child Protection Center. "ChildFirst Interview." Available online: http://www.gundersenhealth.org/ncptc/childfirst (accessed on 11 July 2014).

56. Poole, Debra, and Michael Lamb. Investigative Interviews of Children. Washington, D.C.: American Psychological Association, 1998.

57. Everson, Mark, Chris Ragsdale, and Scott Snider. RADAR: Child Forensic Interview Pocket Guide. Chapel Hill: North Carolina Conference of District Attorneys, 2014.

58. Lyon, Thomas. "Interviewing children." Annual Review of Law and Social Science, 2015, in press.

59. Ministry of Justice. "Achieving Best Evidence in Criminal Proceedings.” 2011. Available online: http://www.justice.gov.uk/downloads/victims-and-witnesses/vulnerable-witnesses/achievingbest-evidence-criminal-proceedings.pdf (accessed on 8 August 2014).

60. Lyon, Thomas, and Karen Saywitz. "Reducing maltreated children's reluctance to answer hypothetical oath-taking questions." Law and Human Behavior 25 (1999): 81-92.

61. Lyon, Thomas. "Children's competency to take the oath." APSAC Advisor 1 (1995): 4-8.

62. Lyon, Thomas, and Karen Saywitz. "Qualifying Children to Take the Oath: Materials for Interviewing Professionals.” Available online: http://works.bepress.com/thomaslyon/9 (accessed on 14 May 2000). 
63. Lyon, Thomas D., and Angela Evans. "Young Children's Understanding That Promising Guarantees Performance: The Effects of Age and Maltreatment." Law and Human Behavior 38 (2014): 162-70.

64. Faller, Kathleen Coulborn. "Chapter 8, Questions.” In Interviewing Children about Sexual Abuse: Controversies and Best Practice. New York: Oxford University Press, 2007, pp. 90-109.

65. American Professional Society on the Abuse of Children (APSAC). "Practice Guidelines: Psychosocial Evaluation of Suspected Sexual Abuse in Young Children.” 1990. Available online: http://www.apsac.org/practice-guidelines (accessed on 12 May 2014).

66. American Professional Society on the Abuse of Children (APSAC). "Practice Guidelines: Psychosocial Evaluation of Suspected Sexual Abuse in Young Children, 2nd ed.” 1997. Available online: http://www.apsac.org/practice-guidelines (accessed on 12 May 2014).

67. American Professional Society on the Abuse of Children (APSAC). "Practice Guidelines: Forensic Interviewing in Cases of Suspected Child Abuse.” 2012. Available online: http://www.apsac.org/ practice-guidelines (accessed on 12 May 2014).

68. Home Office. Memorandum of Good Practice on Video Recorded Interviews with Child Witnesses in Criminal Proceedings. London: Her Majesty's Stationery Office, 1992.

69. Ministry of Justice. "Achieving the Best Evidence in Criminal Proceedings 2011: Conducting Interviews with Children." Available online: http://1lrscb.proceduresonline.com/chapters/ g_achv_best_evid.html\#conducting_interv_ch (accessed on 12 August 2014).

70. CornerHouse. "Interagency Child Abuse Evaluation Center." Available online: http://www.cornerhousemn.org/timeline.html (accessed on 13 August 2014).

71. Vieth, Victor. "Letter to the Editor." Child Abuse \& Neglect 32 (2008): 1003-06.

72. Toth, Patti. "Comparing the NICHD and RATAC Child Forensic Interview Approaches-Do the Differences Matter?" The Link ISPCAN Newsletter. Northern Spring/Southern Autumn 1 (2011): 4-6.

73. Anderson, Jennifer. CornerHouse, Minneapolis, MI, USA. Email communication, 13 January 2012.

74. Rapport, Anatomy Identification, Touch Inquiry, Abuse Scenario, and Closure (RATAC). "CornerHouse/Finding Words Training Manual." Available online: http://rtmq.infosathse.com/ Kansas/ratac.htm (accessed on 18 December 2014).

75. National Children's Advocacy Center. "Forensic Interviewing Training Materials." Available online: http://www.nationalcac.org/images/pdfs/TrainingandConferences/NCAC-Training/Forensic InterviewingOfChildren/TrainingMaterials-BFI/2014TrainingMaterials/NCAC\%20Child\% 20Forensic\%20Interview\%20Structure\%202012.pdf (accessed on 20 August 2014).

76. Anderson, Gwendolyn, Jennifer Anderson, and Jane Gilgun. "The Influence of Narrative Practice Techniques on Child Behaviors in Forensic Interviews.” Journal of Child Sexual Abuse 23 (2014): 615-34.

77. Anderson, Jennifer. "Recent Changes to the CornerHouse Forensic Interview Protocol." Update 24 (2014): 1-3.

78. CornerHouse. "Forensic Interview Protocol." 2013. Available online: http://www.cornerhousemn.org/forensicinterviews.html (accessed on 13 August 2014).

79. First Witness - Child Advocacy Center. "First Witness Forensic Interview Training." Available online: http://www.firstwitness.org/child-forensic-interview-training/ (accessed on 13 August 2014). 
80. Gundersen National Child Protection Training Center. "ChildFirst ${ }^{\mathrm{TM}}$ Protocol.” Available online: http://www.gundersenhealth.org/ncptc/childfirst (accessed on 13 August 2014).

81. Finkelhor, David. Childhood Victimization: Violence, Crime, and Abuse in the Lives of Young People. New York: Oxford University Press, 2008.

82. Pipe, Margaret Ellen, Michael Lamb, Yael Orbach, and Ann-Christian Cederborg. Child Sexual Abuse: Disclosure, Delay, and Denial. New York: Taylor and Francis Psychology Press, 2007.

83. "NICHD Protocol and Translated Versions." Available online: http://nichdprotocol.com/thenichd-protocol/ (accessed on 20 August 2014).

84. "NICHD Protocol Research.” Available online: http://nichdprotocol.com/peer-reviewed-research/ (accessed on 20 August 2014).

85. Lamb, Michael, Irit Hershkowitz, Yael Orbach, and Phillip Esplin. Tell Me What Happened: Structured Investigative Interviews of Child Victims and Witnesses. West Sussex: Wiley-Blackwell, 2008.

86. Sternberg, Kathleen, Michal Lamb, Irit Hershkowitz, Liora Yudilevitch, Yael Orbach, Phillip Esplin, and Meir Hovav. "Effects of introductory style on children's abilities to describe experiences of sexual abuse." Child Abuse and Neglect 21 (1997): 1133-46.

87. Sternberg, Kathleen, Michael Lamb, Yael Orbach, Phillip Esplin, and Suzanne Mitchell. "Use of a structured investigative protocol enhances young children's responses to free recall prompts in the course of forensic interviews." Journal of Applied Psychology 86 (2001): 997-1005.

88. Faller, Kathleen Coulborn. "Chapter 9: Media for Interviewing Children." In Interviewing Children about Sexual Abuse: Controversies and Best Practice. Edited by Kathleen Coulborn Faller. New York: Oxford University Press, 2007, pp. 110-41.

89. Bruck, Maggie, Stephen Ceci, Emmet Francoeur, and Ashley Renick. "Anatomically detailed dolls do not facilitate preschoolers' reports of a pediatric examination involving genital touching." Journal of Experimental Psychology: Applied 1 (1995): 95-109.

90. Bruck, Maggie, Stephen Ceci, and Emmet Francoeur. "Children's use of anatomically detailed dolls to report genital touching in a medical examination: Developmental \& gender comparisons." Journal of Applied Experimental Psychology 6 (2000): 74-83.

91. Lamb, Michael, Irit Hershkowitz, Kathleen Sternberg, Barbara Boat, and Mark Everson. "Investigative interviews of alleged sexual abuse victims with and without anatomical dolls." Child Abuse and Neglect 20 (1996): 1239-47.

92. Thierry, Karen L., Michael E. Lamb, Yael Orbach, and Margaret-Ellen Pipe. "Developmental Differences in the Function and Use of Anatomical Dolls during Interviews with Alleged Sexual Abuse Victims." Journal of Consulting and Clinical Psychology 73 (2005): 1125-34.

93. Aldridge, Jan, Michael Lamb, Kathleen Sternberg, Yael Orbach, Phillip Esplin, Lynn Bowler. "Using a human figure drawing to elicit information from alleged victims of child sexual abuse." Journal of Consulting and Clinical Psychology 72 (2004): 304-16.

94. Katz, Carmit, and Irit Hershkowitz. "The effects of drawing on children's accounts of sexual abuse." Child Maltreatment 15 (2010): 171-79.

95. Hershkowitz, Irit, Yael Orbach, Michael Lamb, Margaret-Ellen Pipe, Kathleen Sternberg, and Dvora Horowitz. "Dynamics of forensic interviews with suspected abuse victims who do not disclose." Child Abuse \& Neglect 30 (2006): 753-70. 
96. Lamb, Michael E., Irit Hershkowitz, and Thomas Lyon. "Interviewing victims and suspected victims who are reluctant to talk." APSAC Advisor 25 (2013): 16-19.

97. Hershkowitz, Irit, Michael Lamb, Carmit Katz, and Lindsey Malloy. "Does enhanced rapport-building alter the dynamics of investigative interviews with suspected victims of intrafamilial abuse?" Journal of Police and Criminal Psychology 10 (2013): 27-36.

98. Hershkowitz, Irit, Michael Lamb, and Carmit Katz. "Allegation Rates in Forensic Child Abuse Investigations: Comparing the Revised and Standard NICHD Protocols." Psychology, Public Policy, and Law 2 (2014): 336-44.

99. Poole, Debra, and Michael Lamb. "Chapter 4: A Flexible Interview Protocol." In Investigative Interviews of Children. Edited by Debra Poole and Michael Lamb. Washington, D.C.: American Psychological Association, 1998, pp. 105-12.

100. Child Abuse Training Service. "Prosecuting Attorneys' Association of Michigan." Available online: http://www.michiganprosecutor.org/index.php?home $=$ cats\&activitylist $=Y$ (accessed on 9 September 2014).

101. "APSAC's Child Forensic Interview Clinic." Available online: http://www.apsac.org/mc/ community/eventdetails.do? eventId=390153\&orgId $=$ apsac\&recurringId $=0 \quad$ (accessed $\quad$ on 10 September 2014).

102. National Children's Advocacy Center. "Forensic Interview of Children Training." Available online: http://nationalcac.org/events/bfi-training.html (accessed on 10 September 2014).

103. CornerHouse "Training." Available online: http://www.cornerhousemn.org/training.html (accessed on 10 September 2014).

104. FirstWitness. "Training.” Available online: http://www.firstwitness.org/child-forensic-interviewtraining/ (accessed on 10 September 2014).

105. Gunderson National Child Protection Training Center. "Training." Available online: http://www.gundersenhealth.org/ncptc/trainings (accessed on 10 September 2014).

106. Midwest Region Children's Advocacy Center. "Key Survey Findings National Multi-Site Survey of Children's Advocacy Centers." 2013. Available online: http://www.mrcac.org/content/ uploads/2014/02/2013-Key-Survey-Findings.FINAL_.pdf (accessed on 10 September 2014).

107. National Children's Advocacy Center. Forensic Interviewing Practices in Children's Advocacy Centers. Huntsville: National Children's Advocacy Center, 2011.

108. La Rooy, David, Michael E. Lamb, and Amina Memon. "Forensic Interviews with Children in Scotland: A Survey of Interview Practices among Police." Journal of Police and Criminal Psychology 28 (2010): 28-34.

109. Sternberg, Kathleen, Michael Lamb, Graham Davies, and Helen Westcott. "The Memorandum of Good Practice: Theory versus Application." Child Abuse and Neglect 25 (2001): 669-81.

110. Lamb, Michael, Kathleen Sternberg, Yael Orbach, Phillip Esplin, and Suzanne Mitchell. "Is ongoing feedback necessary to maintain the quality of investigative interviews with allegedly abused children?" Applied Developmental Science 6 (2002): 35-41.

111. Lamb, Michael, Kathleen Sternberg, Yael Orbach, Irit Hershkowitz, Dvora Horowitz, and Phillip Esplin. "The effects of intensive training and ongoing supervision on the quality of investigative interviews with alleged sex abuse victims." Applied Developmental Science 6 (2002): 114-25. 
112. La Rooy, David, Michael Lamb, and Margaret Ellen Pipe. "Repeated Interviewing: A critical evaluation of the risks and potential benefits." In Child Sexual Abuse: Research, Evaluation, and Testimony for the Courts. Edited by Kathryn Kuehnle and Mary Connell. Hoboken: John Wiley, 2008, pp. 327-64.

113. La Rooy, David, Carmit Katz, Lindsey Malloy, and Michael Lamb. "Do we need to rethink guidance on repeated interviews?" Psychology, Public Policy \& the Law 16 (2010): 373-92.

114. Javonda Williams, Deborah Nelson-Gardell, Kathleen Coulborn Faller, Linda Cordisco-Steele, and Amy Tishelman. "Is There a Place for Extended Assessments for Evaluating Concerns about Child Sexual Abuse? Perceptions of 1294 Child Maltreatment Professionals." Journal of Forensic Social Work 3 (2014): 88-105.

115. Faller, Kathleen Coulborn, and Debra Nelson-Gardell, "Extended evaluations in cases of child sexual abuse: How many sessions are sufficient?" Journal of Child Sexual Abuse: Research, Treatment, \& Program Innovations for Victims, Survivors \& Offenders 19 (2010): 648-68.

116. Lamb, Michael E., and Michelle E. Garretson. "The effects of interviewer gender and child gender on the informativeness of alleged child sexual abuse victims in forensic interviews." Law and Human Behavior 27 (2003): 157-71.

117. Springman, Rachael E., Jeffrey N. Wherry, and Paul C. Notaro. "The Effects of Interviewer Race and Child Race on Sexual Abuse Disclosures in Forensic Interviews." Journal of Child Sexual Abuse: Research, Treatment \& Program Innovations for Victims, Survivors \& Offenders 15 (2006): 99-116.

118. Kinnear, Karen. Child Sexual Abuse: A Reference Handbook. Santa Barbara: ABC-CLIO, Inc., 2007.

(C) 2014 by the author; licensee MDPI, Basel, Switzerland. This article is an open access article distributed under the terms and conditions of the Creative Commons Attribution license (http://creativecommons.org/licenses/by/4.0/). 